\title{
Leaders
}

\section{Autoantibodies and overlap syndromes in autoimmune rheumatic disease}

\author{
E C Jury, D D’Cruz, W J W Morrow
}

\begin{abstract}
Many patients diagnosed with autoimmune rheumatic disease cannot be categorised easily into one of the established clinical entities such as systemic lupus erythematosus, dermatomyositis, or systemic sclerosis. The term "overlap syndrome" has been increasingly used to identify such patients and is useful in terms of clarifying prognosis and facilitating disease management. This article reviews overlap syndrome in autoimmune rheumatic disease, with particular emphasis on the associated serological markers.
\end{abstract}

(f Clin Pathol 2001;54:340-347)

Keywords: autoantibodies; overlap syndromes; autoimmune rheumatic disease

Centre for

Rheumatology

Research, University

College, London

W1T 4JF, UK

E C Jury

Louise Coot Lupus Unit, St Thomas's

Hospital, London

SE1 7EH, UK

D D’Cruz

Department of

Immunology, St

Bartholomew's and

The Royal London

School of Medicine

and Dentistry

W J W Morrow

Correspondence to:

Ms Jury

e.jury@ucl.ac.uk

Accepted for publication 20 September 2000

The complexity of autoimmune disease is formidable and although the precise role of autoantibodies in immunopathological processes remains uncertain, there is little doubt that they contribute to disease advancement. The formation of autoantibodies is a normal physiological process: however, excessive production of such antibodies can be harmful, resulting in disease or injury. Autoantibodies may cause damage by reacting directly against a specific tissue or by the formation and deposition of circulating immune complexes in the kidney, skin, joint, and nervous system. The production of autoantibodies might be secondary to tissue damage or induced by independent pathogenic factors; organ specific and/or nonorgan specific autoantigens may be involved.

Autoimmune rheumatic disorders are characterised by autoantibodies to non-organ specific antigens, specifically, antigens occurring in nucleated cells or among circulating plasma

Table 1 Overlap syndromes in autoimmune rheumatic disease and associated autoantibodies $^{78}$

\begin{tabular}{ll}
\hline Overlap syndrome & Autoantibody directed to \\
\hline Mixed connective tissue disease & nRNP; hnRNP(A2/RA33 complex); U1 \\
& RNA \\
tRNA synthetase syndrome & Jo-1, PL-7, PL-12, OJ, EJ \\
Polymyositis/pulmonary fibrosis & KJ \\
Polymyositis/systemic lupus erythematosus & Ku; PM-Scl; U2 RNP; DNA-PK \\
Polymyositis/scleroderma & Ro/SSA; La/SSB; Ki/SL \\
Secondary Sjögren's syndrome & None identified \\
Rheumatoid arthritis/systemic lupus erythematosus & Centromere; pyruvate dehydrogenase \\
Scleroderma (CREST)/primary biliary cirrhosis & complex \\
& tRNA
\end{tabular}

hnRNP, heterogeneous nuclear ribonuclear protein; PM-Scl, polymyositis-scleroderma overlap syndrome. proteins. This article will consider, primarily, overlap syndromes associated with autoimmune rheumatic disease; specific reference will be made to autoantibody profiles and ramifications for diagnosis and pathogenesis will be discussed. It should be noted that overlap between organ specific autoimmune syndromes, such as myasthenia gravis, Hashimoto's thyroiditis, and insulin dependent diabetes mellitus, is frequently seen; however, a detailed discussion of these conditions is beyond the scope of this paper.

Autoimmune rheumatic diseases are classified using internationally accepted criteria, which frequently incorporate the detection of specific autoantibodies as unique diagnostic markers. Examples include: antidouble stranded DNA (anti-dsDNA) and anti-Smith antigen (anti$\mathrm{Sm}$ ) for establishing a diagnosis of systemic lupus erythematosus (SLE) ${ }^{1}$; the detection of rheumatoid factor in the diagnosis of rheumatoid arthritis (RA) ${ }^{2}$; anticentromere, anti-DNA topoisomerase I, and anti-RNA polymerase I and III antibodies as markers for the scleroderma spectrum of disease; and a group of antibodies including antiliver/kidney microsomes (anti-LKM), antismooth muscle antigen (antiSMA), and antinuclear (ANA), included in diagnostic criteria for autoimmune hepatitis. ${ }^{3}$

However, many patients cannot be assigned to a single disease category. This difficulty has led to the concept of "overlap syndrome", where symptoms from two or more autoimmune conditions are identified in the same patient. Overlap syndromes are commonly associated with autoimmune rheumatic disease, where up to $25 \%$ of patients with early stage or mild variant disease fall into this category. ${ }^{4}$ Overlap syndrome has also been described in patients with autoimmune liver diseases, including autoimmune hepatitis, primary biliary cirrhosis, and primary sclerosing cholangitis (table 1$)^{6}{ }^{6}$

Clinically, it is useful to define overlap syndromes to clarify prognosis and facilitate disease management. ${ }^{9}$ Two approaches can be made when categorising such conditions. The first is by the identification of a pattern of clinical features, and a good example is the tRNA synthetase syndrome. The second is by the initial detection of a unique autoantibody profile combined with specific clinical findings-for example, mixed connective tissue disease (MCTD). ${ }^{10}$ 
Autoimmune rheumatic disease

Connective tissue diseases (CTDs) are characterised by considerable clinical diversity and heterogeneity. Characteristic clinical features and the detection of autoantibodies help to define these disorders and facilitate diagnosis and appropriate treatment. The CTD overlap syndromes are distinguished by the concomitant occurrence of clinical and serological features of the component diseases. Any CTD can be a partner in an overlap disorder-for example, RA is a common partner to SLE, systemic sclerosis, or Sjögren's syndrome (SS). ${ }^{11} 12$

In some cases, overlap syndromes have not been clearly circumscribed or widely accepted and the term "undifferentiated" or "transitional" CTD has been used, implying that they are incompletely developed "classic" CTD, rather than distinct entities with overlapping features. ${ }^{4}$ Disease in patients with undifferentiated CTD might evolve into a more recognisable syndrome, most commonly SLE, myositis, or scleroderma, ${ }^{13-15}$ although one report suggested that most remain undifferentiated. ${ }^{16}{ }^{17}$ Overall, the picture of overlap syndromes with respect to CTD is complex and heterogeneous. Observer bias might play a role in disease classification, so the presence of specific autoantibody profiles might be a useful tool in the diagnosis and management of such patients.

\section{Mixed connective tissue disease}

The existence of MCTD has been the subject of much debate ${ }^{1015} 18^{18}-20$ (reviewed by Smolen and Steiner ${ }^{21}$ ). A detailed discussion is beyond the scope of this review, but suffice to say this syndrome was originally described in 1972 by Sharp and colleagues. ${ }^{22}$ The syndrome is a combination of features typically found in patients with SLE, scleroderma, polymyositis/ dermatomyositis (PM/DM), or RA. The presence of high titre ANA with speckled pattern and antibodies to uridine rich $\mathrm{U} 1$ small nuclear ribonucleoprotein ( $\mathrm{snRNP}$ ) differentiates this MCTD from other CTDs. Three points provide a focus for controversy: first, patients with MCTD may ultimately develop an established CTD, commonly, systemic sclerosis, SLE, or myositis. ${ }^{13-15}$ Second, anti-U1 snRNP antibodies are not confined to MCTD and are found in patients with other CTDs, especially SLE, ${ }^{19} 23$ and, finally, the definition of MCTD is confusing. Although originally described as a benign disorder, considerable organ involvement can accompany this condition and the prognosis may be poor. ${ }^{10}$

Several classification criteria exist for MCTD $^{22} 24$ : : all regard the presence of high titre speckled ANA and anti-U1 snRNP as essential for diagnosis. However, other autoantibodies are seen, specifically antibodies to heterogeneous nuclear ribonucleoprotein (hnRNP), ${ }^{26} \mathrm{U} 1 \mathrm{RNA},{ }^{27}$ phospholipid, ${ }^{28}$ rheumatoid factor, and endothelial cells. ${ }^{29}$ Antibodies to dsDNA and Sm, both specific markers for SLE, are rare. ${ }^{21}$

It is well established that snRNPs are a group of protein particles associated with small RNA molecules in the nucleus of all eukaryotic cells.
The most abundant snRNPs are denoted U1, $\mathrm{U} 2$, U4/U6, and U5 and, together with hnRNP, they form a major component of the spliceosome, where premessenger RNA is processed into mature mRNA. The snRNP spliceosomal complex has several associated common proteins that might also be autoantigenic. Common proteins binding to U1 snRNP particles are represented as $\mathrm{U} 1-70 \mathrm{~K}, \mathrm{U} 1 \mathrm{~A}$, and U1C. Antibodies can be directed to several components of the spliceosome, although with different specificities in different diseases. ${ }^{21}{ }^{29}$ Antibody specificity is normally determined by western blot analysis. Autoantibodies binding to spliceosomal snRNPs (U1, U2, U4/U6, and U5 complexes) are termed anti-Sm antibodies and are associated with SLE. Antibodies recognising the U1 snRNP complex alone are termed anti-nRNP and are considered the hallmark of MCTD (reviewed by Klein Gunneweik and colleagues ${ }^{30}$ ). Anti-nRNP antibodies recognise primarily the $\mathrm{U} 1 \mathrm{snRNP}$ specific proteins $\mathrm{U} 1-70 \mathrm{~K}, \mathrm{U} 1 \mathrm{~A}$, and $\mathrm{U} 1 \mathrm{C}$ and $\mathrm{U} 1$ snRNA. There are conflicting reports detailing the role of anti-nRNP antibodies in predicting disease severity and progression. On balance, evidence suggesting that U1 snRNP antibody titres correlate with clinical events is unconvincing. ${ }^{31}$ Alternatively, antibodies to U1 RNA have been shown to be associated with progressive disease and exacerbation. ${ }^{27}$ Epitope spreading, whereby an immune response to an epitope expands to include associated epitopes on the same molecule, is implicated in the immune response to snRNA and the production of possibly pathogenic antibodies associated with disease. Recent reports suggest that secondary light chain rearrangements in U1RNA reactive $B$ cells, possibly as a result of crossreactivity with viral immunogens, can lead to changing specificity and affinity of anti-RNA antibodies (epitope spreading).$^{32}$ It is interesting to note that long term follow up of clinical and serological findings in patients with MCTD has demonstrated intramolecular spreading of autoantibody reactivity against snRNP polypeptides. This was followed by "epitope contraction" and the ultimate disappearance of anti-snRNP antibodies during prolonged remission in some patients. ${ }^{33}$

Spliceosomal hnRNP, a collection of 30 proteins termed hnRNP A1 to $\mathrm{U}$, is also a common target for autoantibodies in several CTDs, namely, SLE, MCTD, and RA. ${ }^{30}$ Autoantibodies to hnRNP A/B (RA33 complex $)^{26}$ are found in sera from patients with RA, SLE, and MCTD (table 2). In each disease, diverse hnRNP complex epitopes are

Table 2 hnRNP, Sm, and U1 snRNP reactivities of autoantibodies in patients with SLE, RA, and MCTD (adapted from Smolen and Steiner ${ }^{21}$ )

\begin{tabular}{llll}
\hline Autoantibody & MCTD & $R A$ & $S L E$ \\
\hline Anti-hnRNP & + & + & + \\
Anti-Sm & - & - & + \\
Anti-U1 snRNP & + & - & + \\
\hline
\end{tabular}

$\mathrm{hn}$, heterogeneous nuclear; MCTD, mixed tissue connective disease; RA, rheumatoid arthritis; RNP, ribonuclear protein SLE, systemic lupus erythematosus; Sm, Smith antigen; sn, small nuclear. 
recognised-for example, in MCTD, sera appear to recognise a distinctive private epitope on the hnRNP A2 protein. ${ }^{35}$

It has been mentioned previously that a diagnostic feature of MCTD is the production of large quantities of autoantibodies. An imbalance in cytokine synthesis could be an important factor in driving the immune response, resulting in excessive autoantibody production. Hassan and colleagues ${ }^{36}$ have reported an increase in both type 1 and type 2 cytokines in patients with MCTD, including an increase in the cytokines interleukin 10, interferon $\gamma$, and tumour necrosis factor $\alpha$.

Immunogenetic studies have established a linkage between antigens of the major histocompatibility complex (MHC), human leucocyte antigens (HLA) DR4 and DR2, and the presence of autoantibodies to U1 snRNP and U1 snRNA, with the core clinical features of MCTD. ${ }^{18}{ }^{37}$ In the future, genetic studies might be able to predict those patients with overlap syndrome who will eventually develop a classically defined CTD such as scleroderma, SLE, or myositis.

\section{Polymyositis, dermatomyositis, and overlap syndromes}

Autoimmune myositis has two major classifications, polymyositis (PM) and dermatomyositis (DM). Both cause weakness of the proximal muscles and patients have a high frequency of specifically associated autoantibodies to nuclear and cytoplasmic antigens, termed myositis specific antibodies (MSA) (reviewed by Mimori $\left.{ }^{38}\right)$. Myositis specific antibodies are of fundamental importance: they are a tool for diagnosis and patient classification and provide an insight into the pathogenesis of these conditions (for reviews see Targoff ${ }^{39}{ }^{40}$ ). MSA are found almost exclusively in patients with $\mathrm{DM} / \mathrm{PM}$ and associated overlap syndromes. Autoantibodies detected in myositis associated overlap syndromes also include anti-U1 RNP, anti-Ro/SSA, anti-La/SSB, and anti-Sm. However, it is recognised that when autoimmune myositis is associated with another CTD, the full criteria for the concomitant condition may not be met. ${ }^{41}$

\section{tRNA synthetase syndrome}

The tRNA synthetase syndrome is characterised by myositis (PM or DM) (83-100\%), interstitial lung disease (50-80\%), and Raynaud's phenomenon $(60-93 \%) .{ }^{42}$ There is some doubt that this syndrome should be regarded as a true overlap. ${ }^{43}$ The features of this syndrome may be confused with those of SLE, scleroderma or $\mathrm{RA}^{44}$; however, tRNA synthetase syndrome is rarely observed as an overlap syndrome associated with other well defined CTDs. ${ }^{45}{ }^{46}$ tRNA synthetase syndrome is determined serologically by the presence of antibodies against aminoacyl-tRNA synthetases, and diagnosis depends upon the detection of the appropriate autoantibody. The tRNA synthetases are a series of 20 cytoplasmic enzymes that attach tRNA to its corresponding amino acid during the assembly of polypeptides. Antibodies against five different
aminoacyl-tRNA synthetases have been described: anti-Jo-1 (histidyl), PL-7 (threonyl), PL12 (alanyl), OJ (isoleucyl), and EJ (glycyl). Each antibody is independently associated with a distinctive clinical syndrome exhibiting similar clinical features; the synthetase antibodies share immunochemical properties including inhibition of enzymatic function; they do not crossreact with other synthetases; only one antisynthetase antibody will occur in any one patient and they have strong immunogenetic associations. The most predominant antibodies are directed towards Jo-1 (IgG1 subclass); patients with these antibodies tend to have a relatively young age of disease onset compared with other myositis conditions, arthritis is a more common feature, and these antibodies are inclined to be associated with PM rather than DM. ${ }^{40} 42$

Mechanisms of autoimmunity are focused around the concept that MSA play a fundamental role in the disease process. Antisynthetase antibodies each inhibit the enzyme of their antigen specificity, indicating the highly selective nature of the autoimmune response. Enzyme inhibition is proportional to the amount of antibody detected in patients' sera and there are some reports to suggest that antibody titre correlates with disease activity. The autoimmune response is antigen driven, possibly initiated by antigen mimicry, with infectious agents mimicking host antigens and inducing an immune response capable of crossreaction with host proteins (molecular mimicry). Various infectious agents have been implicated including enteroviruses, such as Coxsackie virus, picornaviruses, and retroviruses. Host and viral protein or RNA could interact forming altered host proteins that are immunogenic; picornaviruses have been implicated in this mechanism. Alternatively, Plotz ${ }^{47}$ suggested that anti-idiotype mechanisms might drive the autoimmune response in myositis associated syndromes. Anti-idiotypic antibodies directed towards the binding site of antibodies to viral tRNA might crossreact with synthetases. Finally, a genetic background conducive to the development of MSA is required. HLA associations have been established between B8, DR3, DRw52, and tRNA synthetase syndrome. ${ }^{39} 40$

\section{Other myositis overlaps}

SLE is associated with polymyositis in $4-16 \%$ of cases and some reports have indicated that this overlap syndrome follows a benign course. However, a recent review of cases by Garton and Isenberg ${ }^{48}$ has indicated that no significant difference is seen between overlap and nonoverlap patients. Antibodies to Jo-1 were of low prevalence in this group, although anti- $56 \mathrm{kDa}$ nRNP antibodies were seen with high frequency. Anti-56 kDa nRNP antibodies are associated with myositis occurring together with SLE; the presence of this antibody can help to predict muscle involvement in this group of patients. ${ }^{49}$ Other overlap associations with myositis have been reported but it is doubtful that these reports reflect true overlap syndromes rather than coincidence. 
Table 3 Autoantibodies in scleroderma

\begin{tabular}{ll}
\hline Autoantibody & Clinical importance \\
\hline Anti-DNA topoisomerase I (Scl-70) & Diffuse scleroderma \\
Anticentromere (proteins A, B C) & Limited scleroderma \\
Anti-U3RNP (fibrillarin) & Diffuse scleroderma-severe disease \\
Anti-7-2/8-2 RNP (Th/To) & Limited scleroderma \\
Anti-RNA polymerases I, II, III & Diffuse scleroderma, renal crisis \\
Anti-PM-Scl & Scleroderma overlap \\
Anti-U2 RNP & Scleroderma overlap \\
Anti-Ku & Scleroderma overlap \\
Antipyruvate dehydrogenase complex (M2) & Limited scleroderma and scleroderma overlap \\
\hline
\end{tabular}

Scleroderma and overlap syndromes

Scleroderma or systemic sclerosis is a generalised connective tissue disease involving sclerotic changes in the skin and many other organ systems. The condition encompasses a spectrum of disorders that range from localised forms such as morphoea with limited cutaneous involvement (which may involve the internal organs after long periods) to diffuse cutaneous disease invariably accompanied by early internal organ involvement. ${ }^{41}$ Patients with scleroderma overlap are frequently referred to dermatologists owing to cutaneous symptoms and may be misdiagnosed as having scleroderma. Thus, to establish diagnosis and treatment for patients with scleroderma overlap syndromes, it is important that the associated clinical and serological features are recognised. Clinically, scleroderma has been described in association with SS, SLE, DM, Hashimoto's thyroiditis, and primary biliary cirrhosis. ${ }^{4150}$ Scleroderma overlap syndromes are frequently referred to as MCTDs; however, overlaps also occur in patients who do not have antibodies to nRNP and are associated with ANA of nucleolar staining pattern; table 3 details the full range of associated autoantibodies. ${ }^{51}$

\section{Raynaud's phenomenon}

Raynaud's phenomenon is almost universal in patients with scleroderma and is a feature of many other CTDs and overlap syndromes. Table 4 shows the prevalence of Raynaud's phenomenon in these conditions. It is a disorder characterised by episodic, clearly demarcated, two or three phase colour change of the extremities (usually fingers), in response to cold or emotion. Raynaud's phenomenon occurs in up to $5 \%$ of the normal population, with over $90 \%$ of sufferers being female; the age of onset is usually below 25 years. Five per cent of patients presenting with this condition eventually develop an autoimmune rheumatic disease. The best predictors of progression to CTD are an asymmetrical pattern of Raynaud's, positive ANA, and abnormal nail fold capillary microscopy. ${ }^{41}$

Table 4 Prevalence of Raynaud's phenomenon in autoimmune rheumatic diseases (\%) (adapted from Morrow et al)

\begin{tabular}{ll}
\hline Scleroderma & $>95$ \\
Sjögren's syndrome & $20-50$ \\
Myositis & $20-40$ \\
Systemic lupus erythematosus & $20-30$ \\
Rheumatoid arthritis & $<5$ \\
\hline
\end{tabular}

\section{Scleroderma-polymyositis overlap} syndrome (PM-Scl)

The term "sclerodermatomyositis" was used originally to define a group of patients with features of both scleroderma and dermatomyositis. ${ }^{52}$ The main features of this syndrome are myalgia or myositis, arthralgia, sclerodermalike cutaneous changes, Raynaud's phenomenon, and an association with specific autoantibodies: anti-PM-Scl, anti-Jo-1, anti-Ku, and anti-U2 RNP. The detection of specific autoantibodies or autoantibody profiles assists accurate diagnosis, allowing provision of optimal treatment. Patients with PM-Scl overlap respond to small doses of corticosteroids and do not require intensive treatment; in contrast, patients with scleroderma may not respond to such treatment. ${ }^{51}$

Antibodies to PM-Scl prevail and are found in $40-50 \%$ of patients. ${ }^{7853}$ This antibody was first identified by double immunodiffusion and indirect immunofluorescence, where it produces a characteristic homogeneous nucleolar staining pattern together with weak staining of the nucleoplasm. The $\mathrm{PM}-\mathrm{Scl}$ antigen is located at the site of ribosome assembly in the granular component of the nucleolus, although its function is unknown; the PM-Scl complex may have a role in ribosomal maturation. ${ }^{54}{ }^{55} \mathrm{It}$ is a compound antigen consisting of up to 16 polypeptides with molecular weights ranging from 20 to $110 \mathrm{kDa}$. Autoantibodies are directed predominantly against two molecules of $100 \mathrm{kDa}(95 \%)$ and $75 \mathrm{kDa}(50 \%))^{5455}$ However, although anti-PM-Scl antibodies are found in patients with PM-Scl overlap syndrome in Europe and North America, ${ }^{756}$ they are not found in Japanese patients. This is probably the result of differences in genetic and environmental backgrounds. ${ }^{57}$ Anti-PM-Scl antibodies are strongly associated with HLA DR3; this HLA marker is found rarely in the Japanese population but is common in the normal population of Europe and North America.

Anti-Ku antibodies were described initially in Japanese patients with PM-Scl overlap, although they have since been described in other patient groups. ${ }^{58}$ The target antigen is a heterodimer of $70 \mathrm{kDa}$ and $80 \mathrm{kDa}$ proteins that acts as a regulatory subunit of DNA dependent protein kinase, an enzyme that catalyses the phosphorylation of nuclear proteins. This enzyme complex is involved in transcription, DNA repair, antigen receptor V(D)J recombination, and apoptosis. ${ }^{57}$ These antibodies also present a nucleolar staining pattern by immunofluorescence. Other associated autoantibodies include anti-DNA protein kinase complex antibodies and anti-U2 RNP antibodies, rare antibodies that usually coexist with anti-U1 RNP. ${ }^{8}$

The aetiology and pathogenic mechanisms of PM-Scl overlap remain unknown. A strong association of anti-PM-Scl antibody with HLA DR3 and an increased frequency of HLA $\mathrm{DQA}^{\star} 0501$ suggest a genetic influence. ${ }^{56}$ However, these associations are not absolute and it is probable that several independent factors can result in similar pathogenic mechanisms. ${ }^{59}$ 
Table 5 Autoimmune diseases associated with Sjögren's syndrome (adapted from Morrow et al) ${ }^{41}$

Rheumatoid arthritis

Scleroderma

Systemic lupus erythematosus

Polymyositis/dermatomyositis

Primary biliary cirrhosis

Autoimmune hepatitis

Polyarteritis nodosa

Diabetes

Graves' disease

Myasthenia gravis

Coeliac disease

\section{Other scleroderma overlap syndromes}

An association between limited scleroderma (CREST syndrome), primary biliary cirrhosis, and SS has been reported. ${ }^{50}$ Patients are characterised serologically by the presence of autoantibodies directed against the pyruvate dehydrogenase complex (M2), centromere, and Ro/SSA and/or La/SSB and genetically by an association with HLA Cw6. ${ }^{60}$

Scleroderma and RA may be seen as part of an overlap syndrome. Rheumatoid factor can be detected together with joint damage, but whether this represents a distinct clinical entity or part of the spectrum of scleroderma is unknown. ${ }^{5061}$

\section{SS overlap}

SS is a chronic inflammatory autoimmune disorder affecting the lachrymal and salivary glands and other exocrine organs throughout the body. Dryness of eyes and mouth, chronic fatigue, and arthralgias are the most common features of this disease, which may appear solely, as primary SS, or together with other rheumatic disease as secondary SS. Sicca syndrome describes a limited form of SS restricted to dryness of eyes and mouth, and this syndrome is frequently associated with other autoimmune disease but mainly SLE and RA (table 5). Moutsopoulos and Manoussakis $^{62}$ have suggested additional classification groups for patients with SS based on serological and immunogenetic profiles. They have suggested that they can be divided into three major subsets: those with anti-Ro/SSA and La/SSB antibodies; those with no specific autoantibody response; and those with antibodies against autoantigens such as centromere, mitochondria, and thyroperoxidase. An extensive array of both organ and non-organ specific autoantibodies may be detected in patients with SS (table 6), the most prominent serological feature being the production of rheumatoid factor and ANA associated with antibodies to Ro/SSA and La/SSB. ${ }^{63}$ However, important differences in serological profiles may be found, depending on the nature of the overlap syndrome partner.

Rheumatoid factor is the most common autoantibody found in patients with SS. Differences between SS rheumatoid factor and that produced in patients with RA have been seen, where rheumatoid factor variable genes are close to germ line configurations in SS. ${ }^{64} 65$ Occasionally, very high titres of rheumatoid factor may produce a cryoglobulinaemic vasculitis in these patients.
Anti-Ro/SSA and anti-La/SSB antibodies are not specific for SS but are found commonly in these patients (for a detailed review of these autoantibodies see Scofield and colleagues ${ }^{66}$ ). The Ro autoantigen is an RNP complex binding to the stem-loop structure of human cytoplasmic RNA (hYRNA). Antibodies directed against two Ro polypeptides have been identified-52 kDa (Ro52) and $60 \mathrm{kDa}$ (Ro60) proteins - and there is evidence that the $52 \mathrm{kDa}$ protein binds to the $60 \mathrm{kDa}$ protein, although this is not certain. ${ }^{67}$ The Ro $52 \mathrm{kDa}$ protein has been isolated and characterised; it contains two zinc finger structures and a leucine zipper motif, indicating a role in DNA and RNA binding and protein-protein interaction. La, which may bind transiently to Ro, is an ATP dependent transcription termination factor for RNA polymerase III; it is a $48 \mathrm{kDa}$ protein that binds polyU stretches at the $3^{\prime}$ end of unprocessed polymerase III transcripts. Antibody responses to Ro, $\mathrm{La}$, and other nuclear antigens, such as antiproteasomal antibodies, have been seen to vary between primary SS and SS overlap syndromes. ${ }^{68}{ }^{69}$ Anti-Ro antibodies have been shown to fluctuate in parallel with disease activity, ${ }^{70}$ although this is the exception rather than the rule in clinical practice. The relation between autoantibody profile and disease pathogenesis is not clear; the penetration of these autoantibodies into living cells is powerful evidence that antibodies to Ro and La are implicated pathogenically in disease. For example, in complete neonatal heart block, ${ }^{71}$ a possible mechanism of tissue damage includes the penetration of these autoantibodies into living cells. ${ }^{69}$ In SS, autoantibodies are produced in inflammatory lesions of the salivary glands and the immune response appears to be antigen driven. Infection, resulting in mechanisms such as molecular mimicry, reaction to "altered self", intermolecular and intramolecular spreading might result in antibodies to multiple, linked, self components frequently seen in SS. ${ }^{72}$ Viral infection is strongly implicated as an aetiological factor-for example, Epstein-Barr virus, ${ }^{73}$ retroviruses such as human $\mathrm{T}$ cell leukaemia virus type $1,{ }^{74}$ hepatitis $\mathrm{C},{ }^{76}$ and also organisms such as Helicobacter pylori. ${ }^{77}$ HLA associations with secondary SS have been identified; patients with anti-Ro52 and anti-Ro60 have an increased frequency of DR52, in contrast to associations observed in patients with primary SS. ${ }^{78}$ Several studies have reported an association between HLA DQ and anti-Ro and anti-La antibodies. ${ }^{79}$

Table 6 Organ specific and organ non-specific autoantibodies associated with Sjögren's syndrome overlap syndromes (\%) (adapted from Morrow et al)

$\begin{array}{ll}\text { Antinuclear antibodies }>1 / 80 \text { (titre) } & 60-100 \\ \text { Anti-Ro/SSA } & 5-62 \\ \text { Anti-La/SSB } & 5-42 \\ \text { Anti-Sm } & <5 \\ \text { Anti-RNP } & 5-23 \\ \text { Anti-dsDNA } & 5-56 \\ \text { Rheumatoid factor } & 60-100 \\ \text { Antismooth muscle } & 30 \\ \text { Antisalivary duct } & 50-60 \\ \text { Antithyroperoxidase } & 10-20 \\ \text { Antigastric parietal cell } & 25-30\end{array}$

ds, double stranded; RNP, ribonuclear protein; Sm, Smith antigen 
Alternatively, HLA associations in secondary SS might reflect that of the associated disease. Splitting patients into subgroups based upon HLA associations, autoantibody profiles, and clinical features might provide insight into the pathogenesis of SS overlaps. ${ }^{62}$

\section{RA/SLE overlap}

The existence of patients with a combination of features representing both RA and SLE is acknowledged and termed 'Rhupus'. ${ }^{41} 80 \mathrm{Ar}$ thropathy is associated with $5 \%$ of patients with lupus and is typically non-erosive. Occasionally, patients with SLE develop erosive arthritis with nodules suggesting an overlap with RA. This is seen more frequently as patients become menopausal, when long standing SLE evolves into a more rheumatoid picture, with erosive joint disease. These conditions are rare and there is a paucity of information regarding autoantibody profiles and immunogenetics. It is debatable whether these conditions represent true overlap, rather than chance occurrence of both conditions in the same patient, or evolution of one disease into another. ${ }^{43}$

\section{PBC overlap syndromes}

Primary biliary cirrhosis (PBC), a chronic, inflammatory, cholestatic disease of the liver results in progressive and irreversible destruction of small interlobular and septal bile ducts and liver failure. ${ }^{81}$ The principal treatment for patients with PBC is ursodeoxycholic acid, although advanced disease is treated by liver transplantation. The disease has an autoimmune aetiology and is frequently associated with other autoimmune conditions (table 7). ${ }^{82} 83$ The presence of antimitochondrial antibody (AMA) is a hallmark of PBC and these antibodies are found in $95 \%$ of patients. AMA are present very early in the natural history of the disease, suggesting an intimate role in its pathogenesis. The major antigen termed M2 is located on the inner mitochondrial membrane and is composed of at least five determinants. The major autoantigen is the E2-subunit of the pyruvate dehydrogenase complex (PDC-E2). However, patients with PBC frequently display antibodies to other mitochondrial antigens, such as the $\mathrm{E} 1 \alpha$ and $\mathrm{E} 1 \beta$ subunits of PDC, protein $\mathrm{X}$ of the PDC, and the E2 component of the branched chain $\alpha$-ketoacid dehydrogenase and $\alpha$-ketogluterate dehydrogenase complex. The detection of AMA is the most important diagnostic test for PBC, although these antibodies do not appear to contribute directly to the pathogenesis of the disease. ${ }^{82}$ Recent reports have suggested that biliary epithelial cells are the

Table 7 Autoimmune syndromes associated with primary biliary cirrhosis

Myasthenia gravis

Autoimmune thyroid disease

Mixed connective tissue disease

Systemic lupus erythematosus

Pernicious anaemia

Polymyositis

Limited scleroderma (CREST)

Rheumatoid arthritis

Sjögren's syndrome autoimmune target in PBC. PDC-E2 epitopes recognised by $\mathrm{T}$ cells have been isolated and aberrant expression of MHC class II molecules, intercellular adhesion molecules, and lymphocyte costimulatory molecules has been described. ${ }^{84}$ Antibodies to nuclear antigens are found in up to $50 \%$ of patients with PBC and are useful tools that aid the diagnosis of AMA negative PBC (autoimmune cholangitis). These antibodies can also act as markers of overlaps with autoimmune rheumatic diseases and autoimmune hepatitis (AIH). ${ }^{65}$ PBC specific ANA include antibodies to gp210, nucleoporin $\mathrm{p} 62$, and $\mathrm{Sp} 100^{82}$ and are detected by immunofluorescence.

\section{PBC/CREST overlap}

The association of PBC with limited cutaneous systemic sclerosis or CREST syndrome is well documented. ${ }^{86}$ Patients present with concomitant features of both conditions, although it has been suggested that patients with overlap exhibit a mild form of PBC. Anticentromere antibody (ACA) is seen in $50-80 \%$ of patients with CREST syndrome, but is reported in patients with other autoimmune disease, including up to $29 \%$ of patients with PBC. $^{87}$ There are three major antigenic polypeptides recognised by ACA termed CENP-A, CENP-B, and CENP-C, with an increased reactivity to CENP-C reported in PBC/ CREST overlap syndrome. However, a role for these antibodies in disease pathogenesis has not been ascertained. ${ }^{88}$ AMA are also seen in this overlap population; recently, antibodies to the autoantigens $\mathrm{E} 1 \beta$ and $\mathrm{E} 1 \alpha$ subunit of PDC have been suggested as possible serological indicators for the development of PBC in patients with CREST syndrome. ${ }^{83} 89$ Weak reactivity of almost all sera from patients and controls to the E3 subunit of PDC may shed some light on the mechanism by which immunological tolerance is broken in PBC. An E3 component exists on the membrane of archaebacteria and eubacteria. ${ }^{83}$ Unidentified viral infection has been implicated in the production of clonally expanded CD8 positive $\mathrm{T}$ cells in these patients; the function of these $\mathrm{T}$ cell clones remains unknown but a role in pathogenesis is possible..$^{90}$

Akimoto and colleagues ${ }^{88}$ showed that $75-$ $91 \%$ of patients with PBC/CREST overlap syndrome display features of SS. An overlap of SS with PBC alone has also been reported. ${ }^{91}$

\section{Autoimmune hepatitis (AIH) overlap syndromes}

$\mathrm{AIH}$ is associated with a range of autoantibodies including anti-SMA, ANA, anti-LKM, and anti-asialoglycoprotein receptor. Variant forms of $\mathrm{AIH}$ are common, including combinations of AIH, PBC, primary sclerosing cholangitis, ${ }^{92}$ or chronic viral hepatitis. ${ }^{93} \mathrm{~A}$ detailed discussion of autoimmune hepatitis is beyond the scope of this review (for an overview of associated autoantibodies see Manns, ${ }^{6}$ Czaja ${ }^{94}$ Chazouilleres et $a l,{ }^{95}$ and Lohse and colleagues ${ }^{96}$ ).

Liver disease is also recognised as an important but very rare clinical problem in some patients with SLE, so called lupoid hepatitis. 
Satoh and colleagues ${ }^{97}$ reported a new autoantibody to a tRNA related antigen that appears to be specific for a clinical subset of patients who have a mild form of SLE associated with AIH.

Primary sclerosing cholangitis and $\mathrm{AIH}$, both chronic liver diseases with a probable autoimmune background, have been reported to appear as an overlap. Patients fill the diagnostic criteria for both conditions and autoantibodies associated with both conditions are detected; namely, ANA and anti-SMA associated with $\mathrm{AIH}$, together with perinuclear antineutrophil cytoplasmic antibodies associated with primary sclerosing cholangitis. ${ }^{95}$

\section{Conclusion}

In a clinical setting, autoantibodies are used to establish diagnosis, estimate prognosis, follow disease progression, and monitor treatment regimens. Some are specific disease markers and play a key role in recognised diagnostic criteria. In some cases, it is the profile of autoantibodies, together with other clinical features, that aids diagnosis.

The identification of overlapping clinical features in a given patient is important because treatment might need to be directed specifically at some of these features. The development of myositis in a patient with apparent scleroderma is a useful example where the myositis may respond to active treatment. It is in overlap patients that autoantibody profiles and possibly genetic associations might be most useful in predicting response to treatment and long term prognosis.

Approximately 50 predominantly nuclear proteins act as autoantigens in autoimmune rheumatic diseases; most autoantigens are multiprotein or nucleoprotein complexes with important functions in cell regulation, such as RNA splicing. The basis of pathogenesis is important to determine because it becomes the focus for possible therapeutic intervention. Characterisation of antigens recognised by autoantibodies associated with non-organ specific autoimmune disease, together with the use of molecular biology technology, will help to clarify similarities and differences between various CTDs and overlap syndromes. This might lead to the development of new diagnostic and therapeutic strategies. ${ }^{98} 99$

The authors thank Professor D Isenberg for his advice and support.

1 Tan EM, Cohen AS, Fries JF, et al. The 1982 revised criteria for the classification of systemic lupus erythematosus. ria for the classification of systemid
Arthritis Rheum 1982;25:1271-5.

2 Arnett FC, Edworthy SM, Bloch DA, et al. The American Rheumatism Association 1987 revised criteria for the classification of rheumatoid arthritis. Arthritis Rheum 1987 31:315-24.

3 Johnson PJ, McFarlane IG. Meeting report of the international autoimmune hepatitis group. Hepatology 1993;18 998-1005

4 Cervera R, Khamashta MA, Hughes GVR. Overlap syndromes. Ann Rheum Dis 1990;49:947-8.

5 Maddison PJ. Mixed connective tissue disease, overlap syndromes and eosinophilic fasciitis. Ann Rheum Dis 1991;50. 887-93.

6 Manns MP. Recent developments in autoimmune liver diseases. 7 Gastroenterol Hepatol 1997;12(suppl):S256-71.

7 Mimori T. Structures targeted by the immune system in myositis. Curr Opin Rheumatol 1996;8:521-7.

8 Mimori T. Autoantibodies in connective tissue diseases: clinical significance and analysis of target autoantigens. Intern Med 1999;38:523-32.
9 Fine RM. Overlap syndromes. Int 7 Dermatol 1991;30:479-

10 Isenberg DA, Black C. Naming names! Comment on the rticle by Smolen and Steiner. Arthritis Rheum 1999;42: 191-6.

11 Brand CA, Rowley MJ, Tait BD, et al. Coexistent rheumatoid arthritis and systemic lupus erythematosus: clinical, serological and phenotypic features. Ann Rheum Dis 1992;51:173-6.

12 Horiki T, Moriuchi J, Takaya M, et al. The coexistence of systemic sclerosis and rheumatoid arthritis in five patients: clinical and immunogenetic features suggest a distinct entity. Arthritis Rheum 1996;39:152-6.

13 Nimelstein SH, Brody ST, McShane D, et al. Mixed connective tissue disease: a subsequent evaluation of the original 25 patients. Medicine (Baltimore) 1980;59:239-48.

14 LeRoy EC, Maricq HR, Kalaleh MB. Undifferentiated connective tissue syndromes. Arthritis Rheum 1980;23:341-3.

15 Black C, Isenberg D. Mixed connective tissue diseasegoodbye to all that. Br ₹ Rheumatol 1993;32:348-9.

16 Williams HJ, Alarcon GS, Neuner R, et al. Early undifferentiated connective tissue disease. V. An inception cohort 5 years later: disease remissions and changes in diagnoses in well established and undifferentiated connective tissue diseases. F Rheumatol 1998;25:261-8.

17 Alarcon GS. Unclassified or undifferentiated connective tissue disease. Baillieres Best Practice and Research in Clinical Rheumatology 2000;14:125-37.

18 Sharp GC, Hoffman DO. Clinical, immunologic and immunogenetic evidence that mixed connective tissue disease is a distinct entity: comment on the article by Smolen and Steiner. Arthritis Rheum 1999;42:190-1.

19 Van den Hoogen FHJ, van de Putte LBA. Is mixed connective tissue disease a myth? In: Isenberg DA, Tucker LB, eds. tive tissue disease a myth? In: Isenberg DA, Tucker LB, eds.
Controversies in rheumatology. London: Dunitz, 1997:87-95.

20 Controversies in rheumatology. London: Dunitz, 1997:87-95. dromes. Baillieres Best Practice and Research in Clinical Rheumatology 2000;14:111-24.

21 Smolen JS, Steiner G. Mixed connective tissue disease: to be or not to be? Athritis Rheum 1998;41:768-77.

22 Sharp GC, Irvin WS, Tan EM, et al. Mixed connective tissue disease: an apparently distinct rheumatic disease syndrome associated with a specific antibody to an extractable nuclear antigen. Am F Med 1972;52:148-59.

23 Tan EM. Antinuclear antibodies: diagnostic markers for autoimmune diseases and probes for cell biology. $A d v$ Immunol 1989;52:148-51.

24 Alarcon-Segovia D, Villarreal M. Classification and diagnostic criteria for mixed connective tissue diseases. In: Kasukawa R, Sharp GC, eds. Mixed connective tissue diseases and anti-nuclear antibodies. Amsterdam: Elsevier, 1987:3340 .

25 Kasukawa R, Tojo T, Miyawaki S, et al. Preliminary diagnostic criteria for classification of mixed connective tissue disease. In: Kasukawa R, Sharp GC, eds. Mixed connective tissue diseases and anti-nuclear antibodies. Amsterdam: Elsevier, 1987:41-7.

26 Steiner G, Skriner K, Smolen JS. Autoantibodies to the A/B proteins of the heterogeneous nuclear ribonucleoprotein complex: novel tools for the diagnosis of rheumatic diseases. Int Arch Allergy Immunol 1996;111:314-19.

27 Hoet RM, Koornneef DJ, De Rooij LB, et al. Changes in anti-U1 RNA antibody levels correlate with disease activity in patients with systemic lupus erythematosus overlap syndrome. Arthritis Rheum 1992;35:1202-9.

28 Komatireddy GR, Wang GS, Sharp GC, et al. Antiphospholipid antibodies among anti-U1-70kDa autoantibody positive patients with mixed

29 Hassfeld W, Steiner G, Studnicka A, et al. Autoimmune response to the spliceosome: an immunologic link between rheumatoid arthritis, mixed connective tissue disease and systemic lupus erythematosus. Arthritis Rheum 1995;38: $777-85$

30 Klein Gunnewiek JMT, Van De Putte LBA, Van Venrooij WJ. The U1 snRNP complex: an autoantigen in connective tissue diseases. An update. Clin Exp Rheumatol 1997;15: 549-60.

31 Margaux J, Hayem G, Palazzo E, et al. Clinical usefulness of autoantibodies to U1snRNP proteins in mixed connective tissue disease and systemic lupus erythematosus. Rev Rhum Engl Ed 1998;65:378-86.

32 Hoet RMA, Pieffers M, Stassen MHW, et al. The importance of the light chain for the epitope specificity of human anti-U1 small nuclear RNA autoantibodies present in systemic lupus erythematosus patients. F Immunol 1999; 163:3304-12.

33 Burdt MA, Hoffman RW, Deutscher SL, et al. Long term outcome in mixed connective tissue disease: longitudinal clinical and serologic findings. Arthritis Rheum 1999;42: 899-909.

34 Steiner G, Skriner K, Hassfeld W, et al. Clinical and immunological aspects of autoantibodies to RA33/hnRNPA/B proteins - a link between RA, SLE and MCTD. Mol Biol Rep 1996;23:167-71.

35 Barakat S, Briand JP, Abuaf N, et al. Mapping of epitopes on U1 sn RNP polypeptide A with synthetic peptides and autoimmune sera. Clin Exp Immunol 1991;86:71-8.

36 Hassan $\mathrm{AB}$, Ronnelid J, Gunnarsson I, et al. Increased serum levels of immunoglobulins, C-reactive protein, type 1 and type 2 cytokines in patients with mixed connective tissue disease. $f$ A A utoimmun 1998;11:503-8.

37 Hoffman RW, Sharp GC, Deutscher SL. Analysis of anti-U1 RNA antibodies in patients with connective tissue disease: 
association with HLA and clinical manifestations of disease Arthritis Rheum 1995;38:1837-44.

38 Mimori T. Structures targeted by the immune system in myositis. Curr Opin Rheumatol 1996;8:521-27.

39 Targoff IN. Immune manifestations of inflammatory muscle disease. Rheum Dis Clin North Am 1994;20:857-80.

40 Targoff IN. Autoantibodies in polymyositis. Rheum Dis Clin North Am 1992;18:455-82.

41 Morrow WJW, Nelson JL, Watts RA, et al. Sjögren's syndrome. In: Autoimmune rheumatic disease, 2nd ed. Oxford: Oxford University Press, 1999:147-241.

42 Marguerie C, Bunn CC, Copier J, et al. Polymyositis, pulmonary fibrosis and autoantibodies to aminoacyl-tRNA pynthetase. Q $\mathcal{F}$ Med 1990;77:1019-38.

43 Alarcon-Segovia D. Mixed connective tissue disease and overlap syndromes. Clin Dermatol 1994;12:309-16.

44 Miller FW. Myositis specific antibodies: touchstones for understanding the inflammatory myopathies. $\mathscr{F} A M A 1993$ 270:1846-9.

45 O'Neill TW, Maddison PJ. Rheumatoid arthritis associated with myositis and anti-Jo-1 antibody. F Rheumatol 1993;20 $141-3$.

46 Love LA, Leff RL, Fraser DD, et al. A new approach to the classification of idiopathic inflammatory myopathy: myositis-specific autoantibodies define useful homogeneous patient groups. Medicine (Baltimore) 1991;70:360-74.

47 Plotz PH, Autoantibodies are anti-idiotype antibodies to antiviral antibodies. Lancet 1983;ii:824-6.

48 Garton MJ, Isenberg DA. Clinical features of lupus myositis versus idiopathic myositis: a review of 30 cases. Br f Rheumatol 1997;36:1067-74.

49 Ioannou Y, Sultan S, Isenberg DA. Myositis overlap syndromes. Curr Opin Rheumatol 1999;11:468-74

50 Bennett RM. Scleroderma overlap syndromes. Rheumatic Dis Clin North Am 1990;16:185-98.

51 Jablonska S, Chorzelski TP, Blaszczyk M, et al. Scleroderma/ polymyositis overlap syndromes and their immunologic markers. Clin Dermatol 1993;10:443-56.

52 Tuffanelli DL, Winkelmann RK. Systemic scleroderma. A clinical study of 727 cases. Arch Dermatol 1961;84:359-71.

53 Reichlin M, Maddison P, Targoff I, et al. Antibodies to a nuclear/nucleolar antigen in patients with polymyositis nuclear/nucleolar antigen in patients with po
overlap syndromes. F Clin Immunol $1984 ; 4: 40-4$.

54 Bluthner M, Bautz EKF, Bautz FA. Mapping of epitopes recognised by $\mathrm{PM} / \mathrm{Scl}$ autoantibodies with gene-fragment phage display libraries. F Immunol Methods 1996;198:187-98.

55 Alderuccio F, Chan EKL, Tan EM. Molecular characterization of an autoantigen of $\mathrm{PM} / \mathrm{Scl}$ in the polymyositis scleroderma overlap syndrome. F Exp Med 1991;173:94152.

56 Hausmanowa-Petrusewicz I, Kowalska-Oledzka E, Miller $\mathrm{FW}$, et al. Clinical, serologic and immunogenetic features in Polish patients with idiopathic inflammatory myopathies. Arthritis Rheum 1997;40:1257-66.

57 Yamanishi Y, Maeda H, Katayama S, et al. Sclerodermapolymyositis overlap syndrome associated with anti-Ku
antibody and rimmed vacuole formation. $\mathcal{F}$ Rheumatol 1996;23:1991-4.

58 Mimori T, Akizuki $M$, Yamagata $\mathrm{H}$, et al. Characterization of a high molecular weight acidic nuclear protein recognized by autoantibodies in sera from patients with polymyositis-scleroderma overlap. F Clin Invest 1981;68: 611-20.

59 Bunn CC, Black CM. Systemic sclerosis: an autoantibody mosaic. Clin Exp Immunol 1999;117:207-8.

60 Akiyama Y, Tanaka M, Takeishi M, et al. Clinical, serological and genetic study in patients with CREST syndrome. Intern Med 2000;39:451-6.

61 Horiki T, Moriuchi J, Takaya M, et al. The coexistence of systemic sclerosis and rheumatoid arthritis in five patients: clinical and immunogenic features suggest a distinct entity. Arthritis Rheum 1996;39:152-6.

62 Moutsopoulos HM, Manoussakis MN. Lumping or splitting autoimmune rheumatic disorders? Lessons from Sjogren's syndrome. Br F Rheumatol 1998;37:1263-4.

63 Von Muhlen CA, Tan EM. Autoantibodies in the diagnosis of systemic rheumatic diseases. Semin Arthritis Rheum 1995;24:323-58.

64 Elagib KE, Borretzen M, Jonsson R, et al. Rheumatoid factors in primary Sjogren's syndrome (pSS) use diverse VH region genes, the majority of which show no evidence of somatic hypermutation. Clin Exp Immunol 1999;117:388-94.

65 Elagib KEE, Tengner PIA, Levi M, et al. Immunoglobulin variable genes and epitope recognition of human monoclonal anti-Ro 52-kd in primary Sjogrens syndrome. Arthritis Rheum 1999;42:2471-81.

66 Scofield RH, Farris AD, Horsfall AC, et al. Fine specificity of the autoimmune response to the Ro/SSA and La/SSB of the autoimmune response to the Ro/SSA and La/SS
ribonucleoproteins. Arthritis Rheum 1999;42:199-209.

67 Kelekar A, Saitta MR, Keene JD. Molecular composition of Ro small ribonucleoprotein complexes in human cells: intracellular localisation of the $60-$ and $52 \mathrm{kD}$ proteins. $\mathcal{F}$ Clin Invest 1994;93:1637-44

68 Ricchiuti V, Briand JP, Meyer O, et al. Epitope mapping with synthetic peptides of $52 \mathrm{kDa} S S A / R o$ protein reveals heterogeneous antibody profiles in human autoimmune sera. Clin Exp Immunol 1994;95:397-407.

69 Feist E, Kuckelkorn U, Dorner T, et al. Autoantibodies in primary Sjogren's syndrome are directed against proteasomal subunits of the $\alpha$ and $\beta$ type. Arthritis Rheum 1999;42: mal subunits.

70 Praprotnik S, Bozic B, Kveder T, et al. Fluctuation of anti-Ro/SS-A antibody levels in patients with systemic lupus erythematosus and Sjogren's syndrome: a prospective study. Clin Exp Rheumatol 1999;17:63-8.

71 Buyon JP. Neonatal lupus syndromes. Curr Opin Rheumatol 1994;6:523-9.

72 Topfer F, Gordon T, McCluskey J. Intra- and intermolecular spreading of autoimmunity involving the nuclear self antigens La (SS-B) and Ro (SS-A). Proc Natl Acad Sci USA 1995;92:875-79.

73 Venables PJW. Polymyositis-associated overlap syndromes. Br f Rheumatol 1996;35:305-6.

74 Tominaga M, Mitita K, Nakamura $\mathrm{H}$, et al. Expression of metalloproteinase-2 (gelatinase A) in labial salivary glands of patients with Sjogren's syndrome with HTLV-1 infection. Clin Exp Rheumatol 1999;17:463-6.

75 Hida A, Kawabe Y, Kawakami A, et al. HTLV-1 associated Sjogren's syndrome is aetiologically distinct from antiRheum Dis 1999;58:320-2

76 Ramos-Casals M, Garcia-Carrasco M, Cervera R, et al. Sjogren's syndrome and hepatitis C virus. Clin Rheumatol Sjogren's syndrom
1999;18:93-100.

77 Aragona P, Magazzu G, Macchia G, et al. Presence of antibodies against Helicobacter pylori and its heat-shock protein 60 in the serum of patients with Sjogren's syndrome. F Rheumatol 1999;26:1306-11.

78 Wilson RW, Provost TT, Bias WB, et al. Sjogren's syndrome. Influence of multiple HLA-D region alloantigens on clinical and serologic expression. Arthritis Rheum 1984;27: $1245-53$.

79 Harley JB, Reichlin M, Arnett FC, et al. Gene interaction at HLA-DQ enhances autoantibody production in primary Sjogren's syndrome. Science 1986;232:1145-7.

80 Hamasaki K, Mimura T, Kanda H, et al. Development of systemic lupus erythematosus in a rheumatoid arthritis patient with anti-ribosomal P protein antibody. Lupus 1997;6:734-6

81 Kaplan MM. Primary biliary cirrhosis. N Engl f Med 1987; 316:521-8.

82 Strassburg CP, Jaeckel E, Manns MP. Anti-mitochondrial antibodies and other immunological tests in primary biliary cirrhosis. Eur 7 Gastroenterol Hepatol 1999;11:595-601.

83 Akimoto $\mathrm{S}$, Ishikawa $\mathrm{O}$, Takagi $\mathrm{H}$, et al. Immunological features of patients with primary biliary cirrhosis (PBC) overlapping systemic sclerosis: a comparison with patients with PBC alone. F Gastroenterol Hepatol 1998;13:897-901.

84 Joplin RE, Neuberger JM. Immunopathology of primary 93.

85 Czaja AJ. Frequency and nature of the variant syndromes of autoimmune liver disease. Hepatology 1998;28:360-5.

86 Powell FC, Schroeter AL, Dickson ER. Primary biliary cirrhosis and the CREST syndrome: a report of 22 cases. $Q \mathcal{F}$ Med 1987;62:75-82.

87 Tubach F, Hatem G, Elias A, et al. Anticentromere antibodies in rheumatologic practice are not consistently associated with scleroderma. Rev Rhum Engl Ed 1997;64:362-7.

88 Akimoto S, Ishikawa O, Muro Y et al. Clinical and immunological characterisation of patients with systemic sclerosis overlapping primary biliary cirrhosis: a comparison with patients with systemic sclerosis alone. F Dermatol 1999;26: $18-22$.

89 Fujimoto M, Sato S, Ihn Hironobu, et al. Autoantibodies to pyruvate dehydrogenase complex in patients with systemic pyruvate dehydrogenase complex in patients with systemic indicator for development of primary biliary cirrhosis. indicator for development of
Arthritis Rheum 1995;38:985-9.

90 Mayo MJ, Jenkins RN, Combes B, et al. Association of clonally expanded $\mathrm{T}$ cells with the syndrome of primary biliary cirrhosis and limited scleroderma. Hepatology 1999;29: 1635-42.

91 Fujikura S, Davis P, Prindiville T, et al. Sjogren's syndrome and primary biliary cirrhosis: presence of autoantibodies to purified mitochondrial 2-OXO acid dehydrogenates. 7 Rheumatol 1990;17:1453-7.

92 Gohlke F, Lohse AW, Dienes HP, et al. Evidence for an overlap syndrome of autoimmune hepatitis and primary sclerosing cholangitis. $\mathcal{F}$ Hepatol 1996;24:699-705.

93 Klein R, Zanger UM, Berg T, et al. Overlapping but distinct specificities of anti-liver-kidney microsome antibodies in autoimmune hepatitis type II and hepatitis $C$ revealed by recombinant native CYP2D6 and novel peptide epitopes. Clin Exp Immunol 1999;118:290-7.

94 Czaja AJ. The variant forms of autoimmune hepatitis. Ann Intern Med 1996;125:588-98.

95 Chazouilleres O, Wendum D, Serfaty L, et al. Primary biliary cirrhosis-autoimmune hepatitis overlap syndrome: clinical features and response to therapy. Hepatology 1998; 28:296-301.

96 Lohse AW, Meyer zum Buschenfelde KH, Franz B, et al. Characterization of the overlap syndrome of primary biliary cirrhosis (PBC) and autoimmune hepatitis: evidence for it being a hepatic form of PBC in genetically susceptible individuals. Hepatology 1999;29:1078-84.

97 Satoh T, Hirakata M, Yoshida T, et al. Systemic lupus erthyematosus associated with autoimmune hepatitis: two cases with novel autoantibodies to transfer RNA-related antigens. Clin Rheumatol 1997;16:305-9.

98 Reeves WH, Satoh M. Features of autoantigens. Mol Biol Rep 1996;23:217-26.

99 Fritzler MJ. Autoantibodies: diagnostic fingerprints and etiologic perplexities. Clin Invest Med 1997;20:50-6. 